\title{
CARACTERÍSTICAS MINERALÓGICAS DE UMA TOPOSSEQUENCIA DE SOLOS DA REGIÃO DE SÃO PEDRO, ESTADO DE SÃO PAULO *
}

\author{
J.L.I. Demattê ** \\ N. HOLOWAYCHUCK $* * *$
}

\begin{abstract}
RESUMO
Foram estudados oito pedons localizados em uma topossequência de aproximadamente $25 \mathrm{~km}$ de extensão, na região de São Pedro, Estado de São Paulo, indo do rio Piracicaba, na Depressão Paleozóica até o rio Jacaré-Pupira, no Planalto Ocidental. A fração argila da maioria dos solos estudados é formada principalmente por caulinita e gibbsita. Pedons localizados nas superfícies mais baixas (Pedons 1 a 5 ) possuem baixo teor de gibbsita (menos que 6\%) enquanto que os solos localizados nas altas superfícies (Pedons 6,7 e 8) possuem teores de gibbsita variando de 12 a $54 \%$. Pedon 3 apresenta uma composição mineralógica diferente dos demais solos; a quantidade de minerais de grade $2: 1$ (mica, vermiculita e montmorilonita) é grande, com teores entre 30 e $70 \%$. Nos demais solos o teor de minerais de grande 2:1 é baixo (menos que $80 \%$ ) representado principalmente pela vermiculita.

Para os solos localizados nas superfícies mais baixas existe correlação entre a mineralogia da argila e as idades das superfícies fisiográficas. Esta relação não é aparente para os solos localizados nas superfícies elevadas. A transformação de caulinita para gibbsita é observada.
\end{abstract}

\section{INTRODUÇÃO}

A região de São Pedro, no Estado de São Paulo tem sido ultimamente objeto de estudos tanto na área geomorfológica (Penteado, 1969) como na pedológica (Demattê, 1975) e recentemente na área das formações superficiais. Esta região tem sido selecionada devido a uma série de razões, entre as quais os seguintes fatores são considerados importantes: a localização da área no desenvolvido vale do rio Piracicaba; proximidades de um centro de pesquisas como a E.S.A. "Luiz de Queiroz", a ampla variação das características dos solos; a variabi-

* Entregue para publicação em 19-1-1977.

* Departamerto de Solos e Geologia, E.E.A. "Luiz de Quejroz", Piracicaba, SP.

** Agronomy Departament, Ohio State University. 
lidade do material superficial; grande variação na topografia e nas características geomorfológicas; as diversas alternativas do uso da terra e na representatividade dos solos para o estado de São Paulo.

Neste trabalho propõe-se estudar as características mineralógicas da fração argila e sua influência na genese de oito solos localizados em uma topossequência que vai do rio Piracicaba, na Depressão Paleozóica, até o rio Jacaré-Pupira no Planalto Ocidental Paulista com uma extensão aproximada de $25 \mathrm{~km}$.

\section{MATERIAL E MÉTODOS}

\section{Características da área e solos}

A área selecionada para o estudo está localizada no município de São Pedro e cerca de $4 \mathrm{~km}$ a oeste desta cidade em direção a São Manoel, no estado de São Paulo. Compreende uma área de aproximadamente $5 \mathrm{~km}$ de largura por $25 \mathrm{~km}$ de comprimento, tendo como limites os riachos Vermelho e do Meio, afluentes do Piracicaba. O clima atual é subtropical úmido com uma estação seca no inverno; a precipitação média anual é de $1200 \mathrm{~mm}$ e a temperatura média anual de $19,5^{\circ} \mathrm{C}$.

Após os estudos de campo a área foi dividida em seis superfícies fisiográficas distintas e nestas superfícies é que foram amostrados os oito solos (Fig. 1A). O solo 1, localizado na superfície I, próximo ao rio Piracicaba, é um solo profundo, com textura média, possue um horizonte argílico a $58 \mathrm{~cm}$ de profundidade. O pedon 2, localizado na superfície II que corresponde ao segundo terraço, é um oxissol de textura média, profundo e de baixa fertilidade. Até a profundidade de $4 \mathrm{~m}$ o pedon é homogeneo, sendo que além desta profundidade ele apresenta uma cascalheira de aproximadamente $1 \mathrm{~m}$ de espessura. O pedon 3 , situado em uma área muito dissecada possue uma linha de pedras aos $96 \mathrm{~cm}$ de espessura. Abaixo desta linha de pedras o material de origem está representado pelo arenito e siltito da formação Botucatu. O solo é morfologicamente semelhante ao Podzólico Vermelho Amarelo - variação Laras não possuindo, entretanto, horizonte argílico (Demattê, 1975). Os Pedons 4 e 5 são representativos da superfície IV, a mais extensa da área sendo o material representado pela Formacão Rio Claro (Penteado, 1969). Os solos arenosos, profundos, classificados como Regossois. Os Pedons 7 e 8 são os representativos da superfície V. O Pedon 7 é um Latossol Vermelho Amarelo de textura média e o Pedon 8 um Latossol Roxo. A superfície VI, a mais antiga, está representada pelo Pedon 6, um Latossol Vermelho Amarelo de textura média e de origem poligenética. As quatro primeiras superfícies estão localizadas na Depressão Paleozóica enquanto que as demais no Planalto Ocidental (Figura 1B). 


\section{Análise mineralógica da fração argila}

Após a eliminação da matéria orgânica $\left(\operatorname{com} \mathrm{H}_{2} \mathrm{O}_{2}\right)$ e óxido de $\mathrm{Fe}$ livre (ditionito-citrato $\mathrm{Na}$ ) a amostra de solo foi dispersada e a fração argila separada por sifonação. Amostra de argila foi saturada com $\mathbf{M g}$ e os cloretos eliminados. Foi montada diversas amostras orientadas em lâminas de vidro e preparados os seguintes tratamentos: amostra seca a $25^{\circ} \mathrm{C}$, amostra aquecida a $350^{\circ} \mathrm{C}$, amostra aquecida a $550^{\circ} \mathrm{C}$ e amostra glicolada (Jackson, 1965). A amostra foi irradiada no intervalo de 2 a $30^{\circ} 2 \theta$. As determinações quantitativas foram as seguintes: caulinita e gibbsita por análise térmica diferencial (Dixon, 1966), montmorilonita e vermiculita pela CTC (Alexiades e Jackson, 1965); mica, pelo teor de $\mathrm{K}_{2} \mathrm{O}$ e alofana por dissolução seletiva (Alexiades e Jackson, 1966); Fe livre pelo ditionito-citrato (Holmgren, 1967).

\section{RESULTADOS E DISCUSSÃO}

De acordo com os dados obtidos (Quadro 1) os solos estudados podem ser reunidos em dois grupos. Um deles está representado pelos pedons localizados na Depressão Paleozóica (Pedons 1 e 4) e o outro pelos solos localizados no Planalto Ocidental (Pedons 6, 7 e 8).

A caulinita é o mineral mais abundante em todos os pedons das superfícies mais baixas com exceção do Pedon 3 onde apreciáveis quantidades de minerais de grade 2:1 ocorrem. Vermiculita e gibbsita (Fig. 2) são minerais comuns a todos estes solos porém em pequena quantidade. Montmorilonita ocorre em quantidade razoável apenas no Pedon 3 (Figura 2).

Devido as características mineralógiacs diferentes dos demais solos o Pedon 3 pode ser considerado separadamente. $\mathrm{O}$ teor de minerais de grade 2:1 é em certos horizontes superior a 40\%. Examinando-se o teor de mica deste solo observa-se que sua distribuição não é homogênea em profundidade; indicando que o material de origem não é uniforme, fato este concordante com a descrição morfológica (não apresentada) que anotou a presença de uma linha de pedras aos $96 \mathrm{~cm}$ de profundidade. Consequentemente o Pedon 3 é de origem poligenético. A presença de montmorilonita neste solo não é compatível com as atuais condições de formação deste mineral (Keller, 1964). Conclue-se, portanto que este mineral e mesmo a mica foram herdados do material de origem, no caso os sedimentos da Formação Botucatu. Almeida (1964) salienta que tanto as facies fluvial e lacustrina do Botucatu tiveram material calcário em sua composição. Nestas condições, ou seja, drenagem impedida e riqueza em cálcio a montmorilonita pode-se formar no material de origem. 


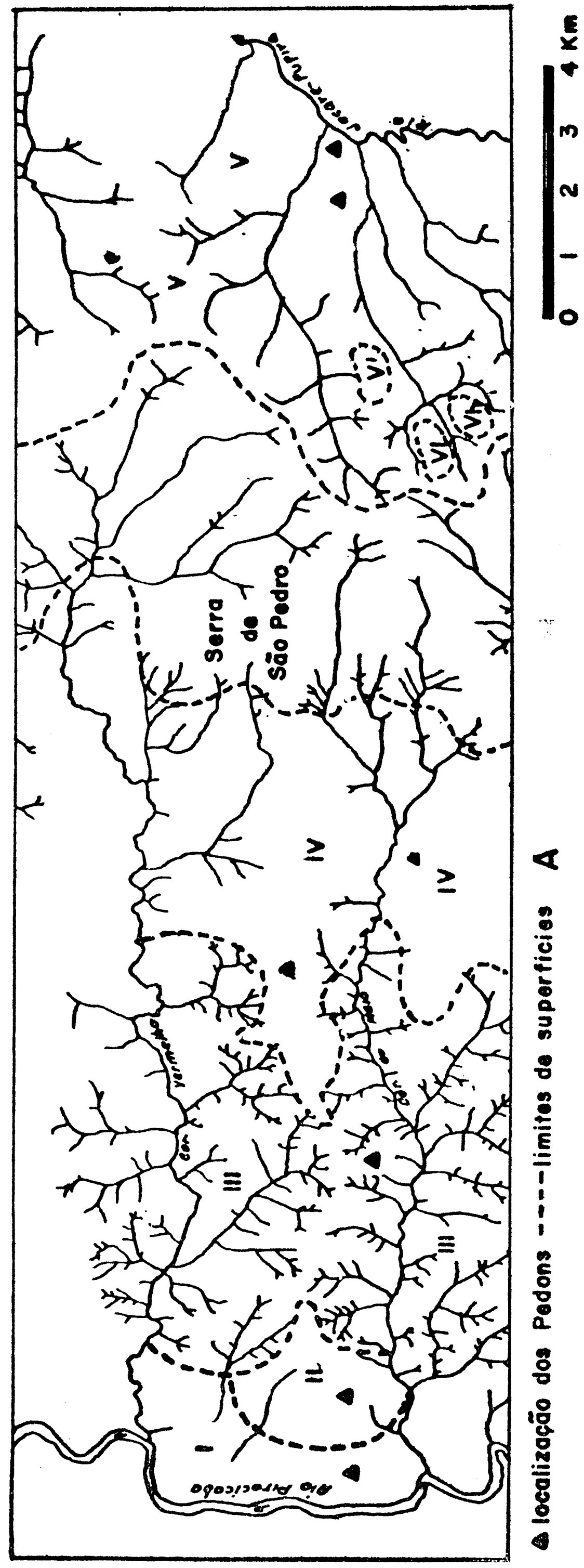




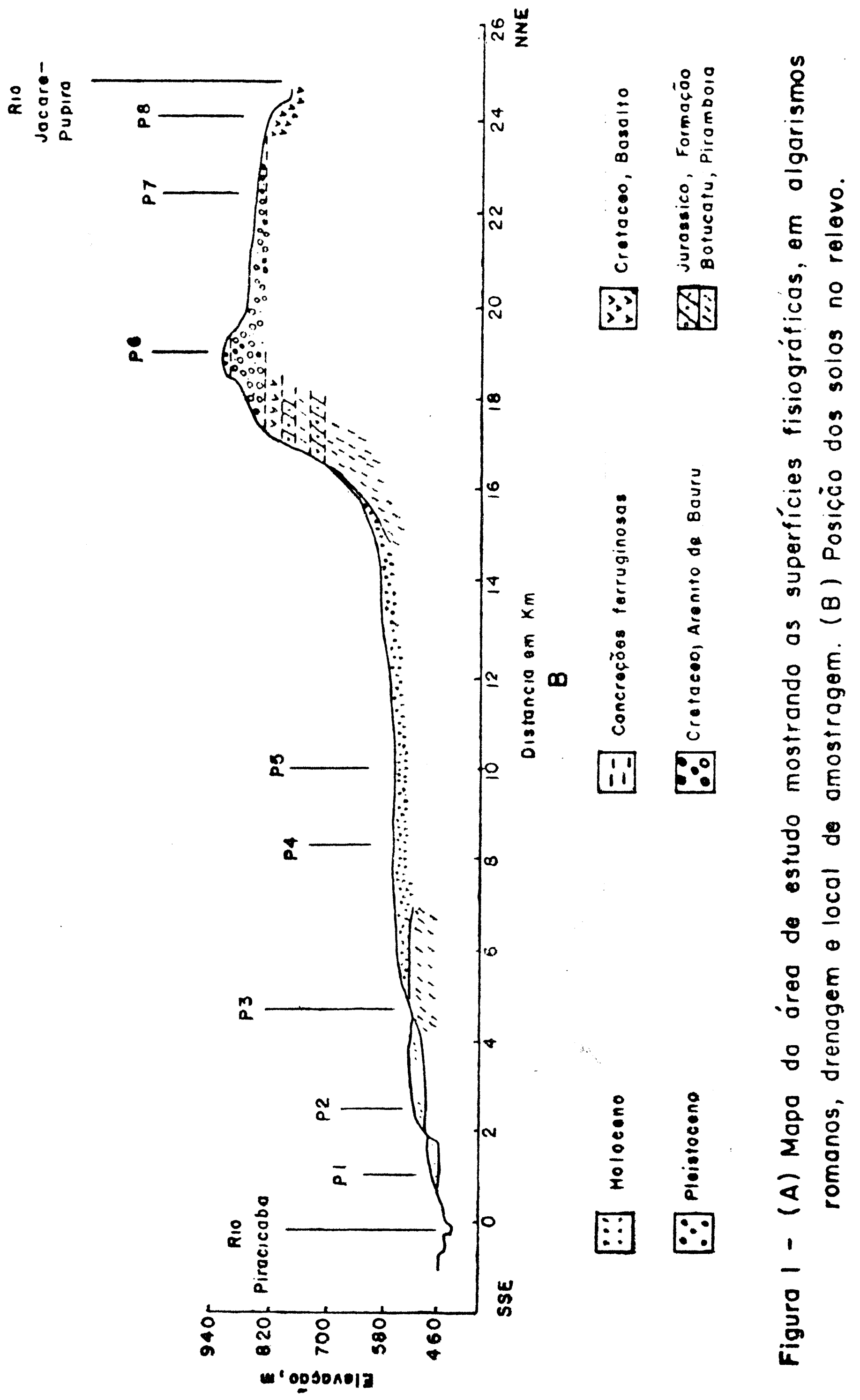




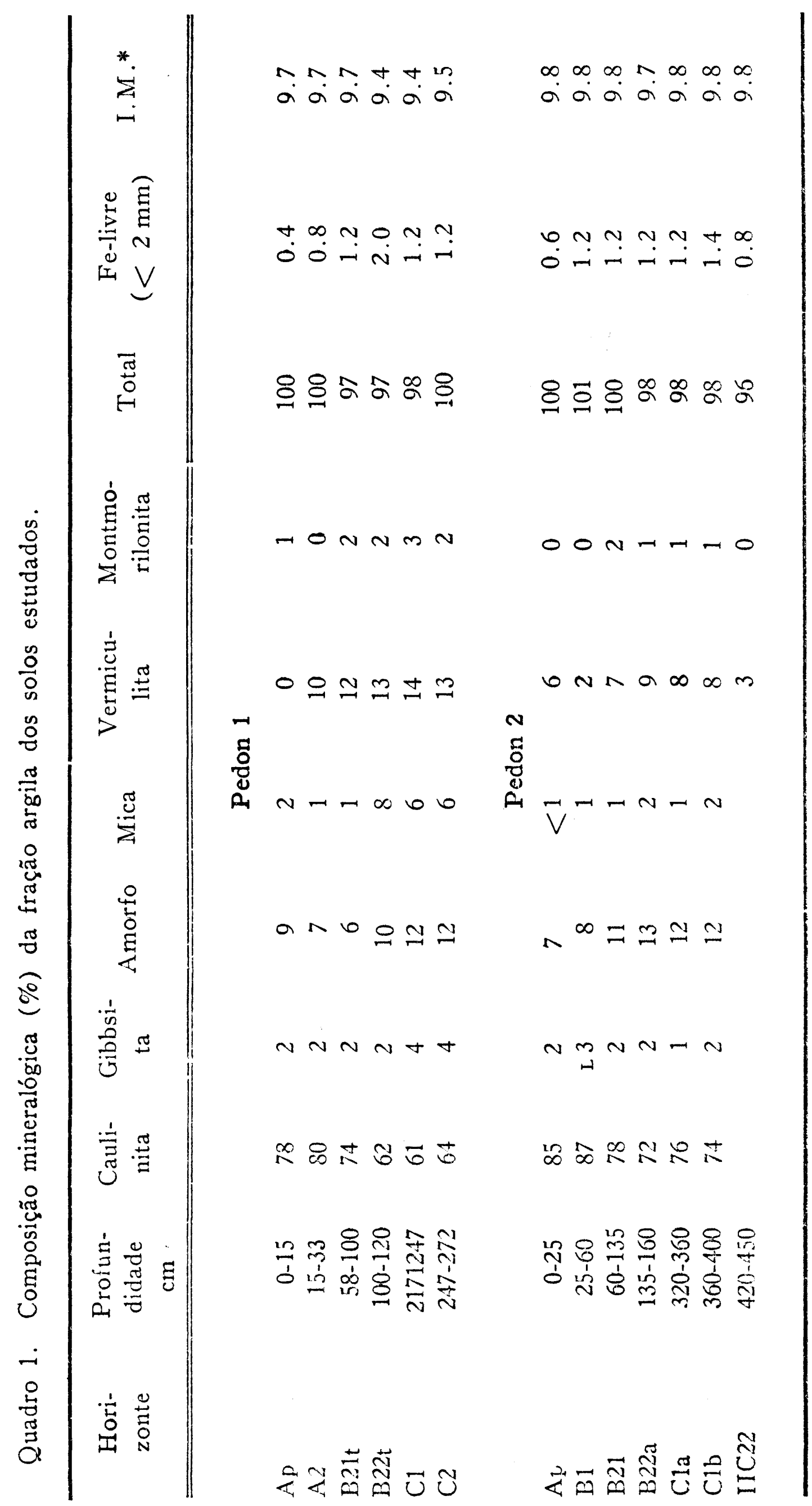




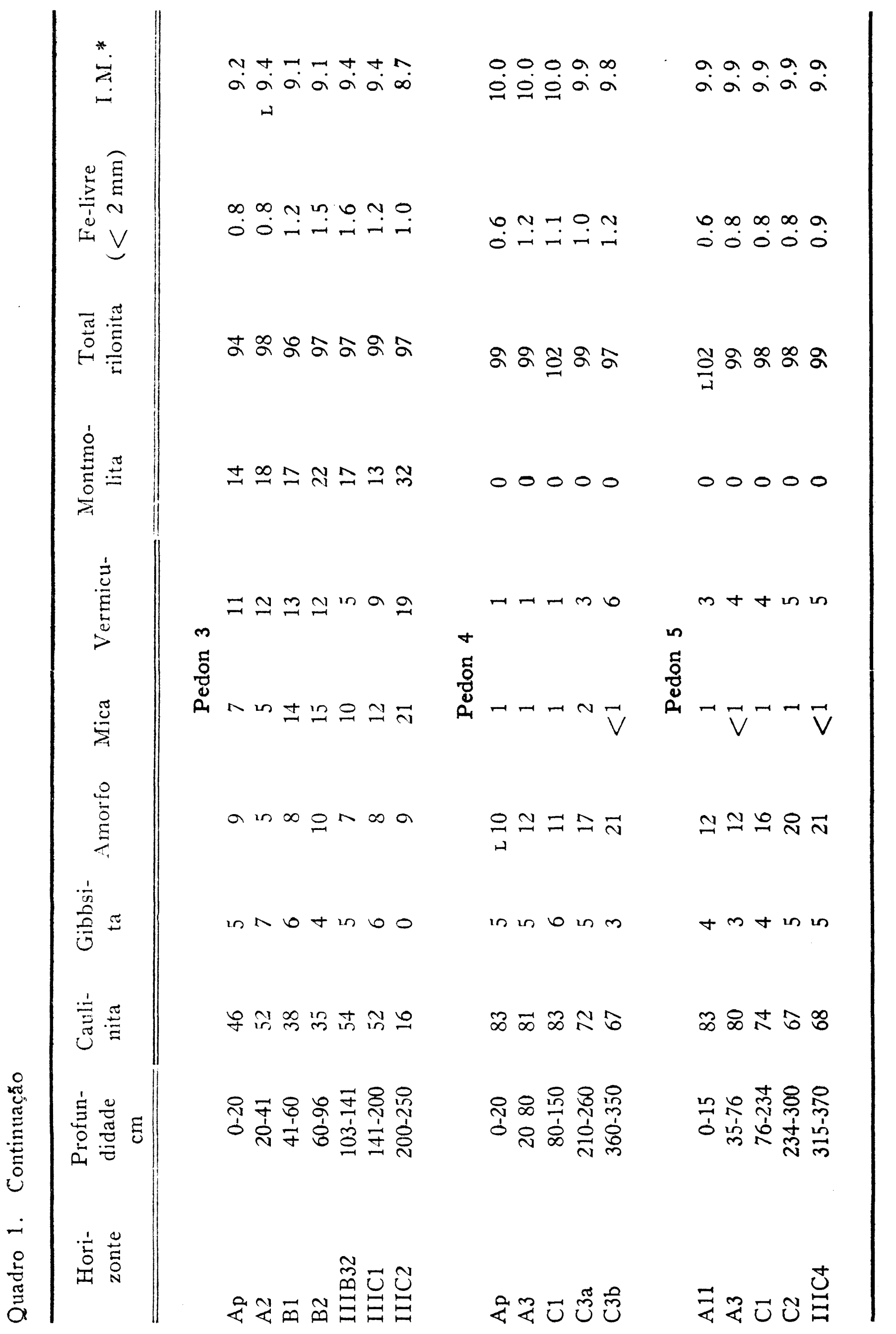




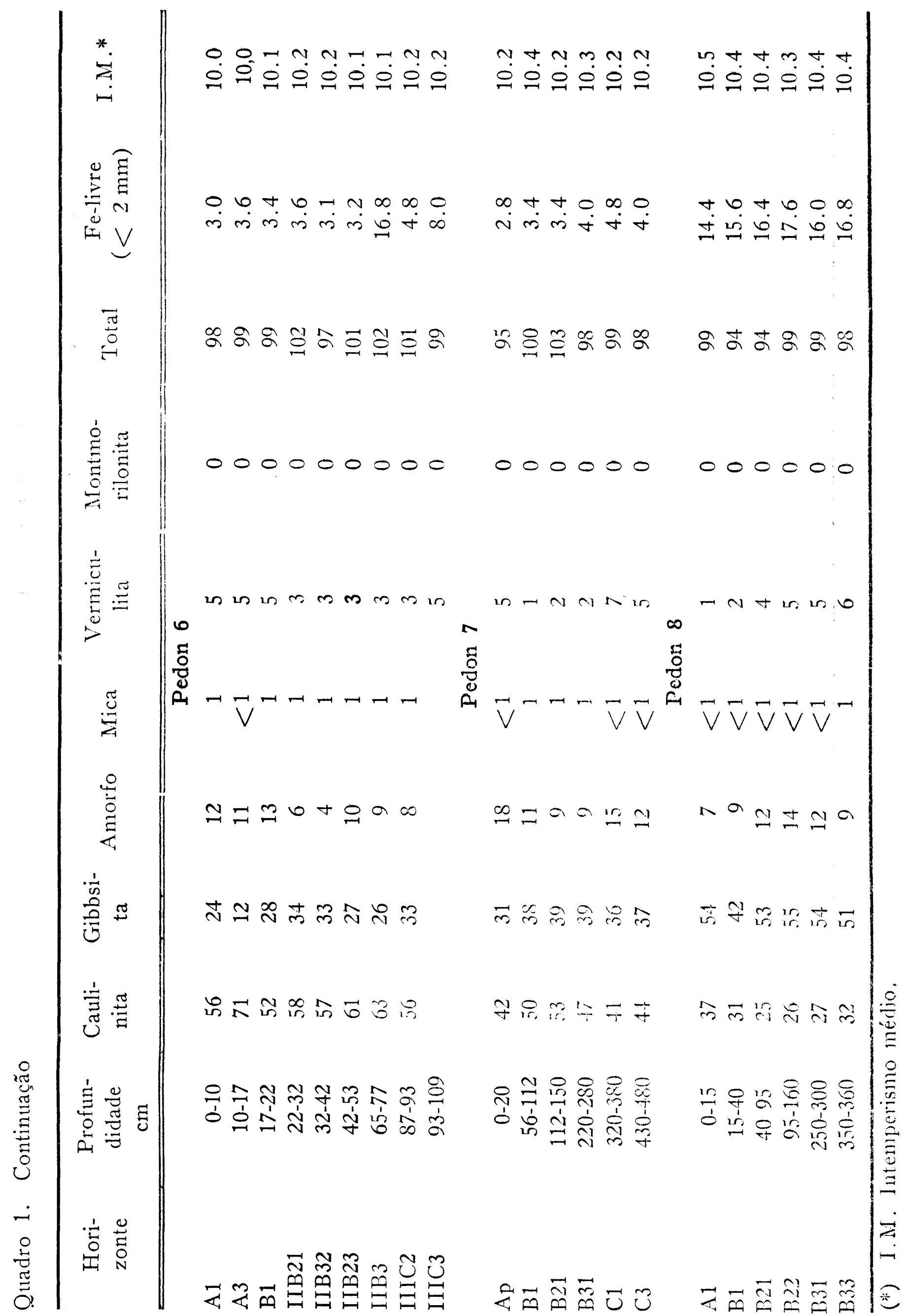


A

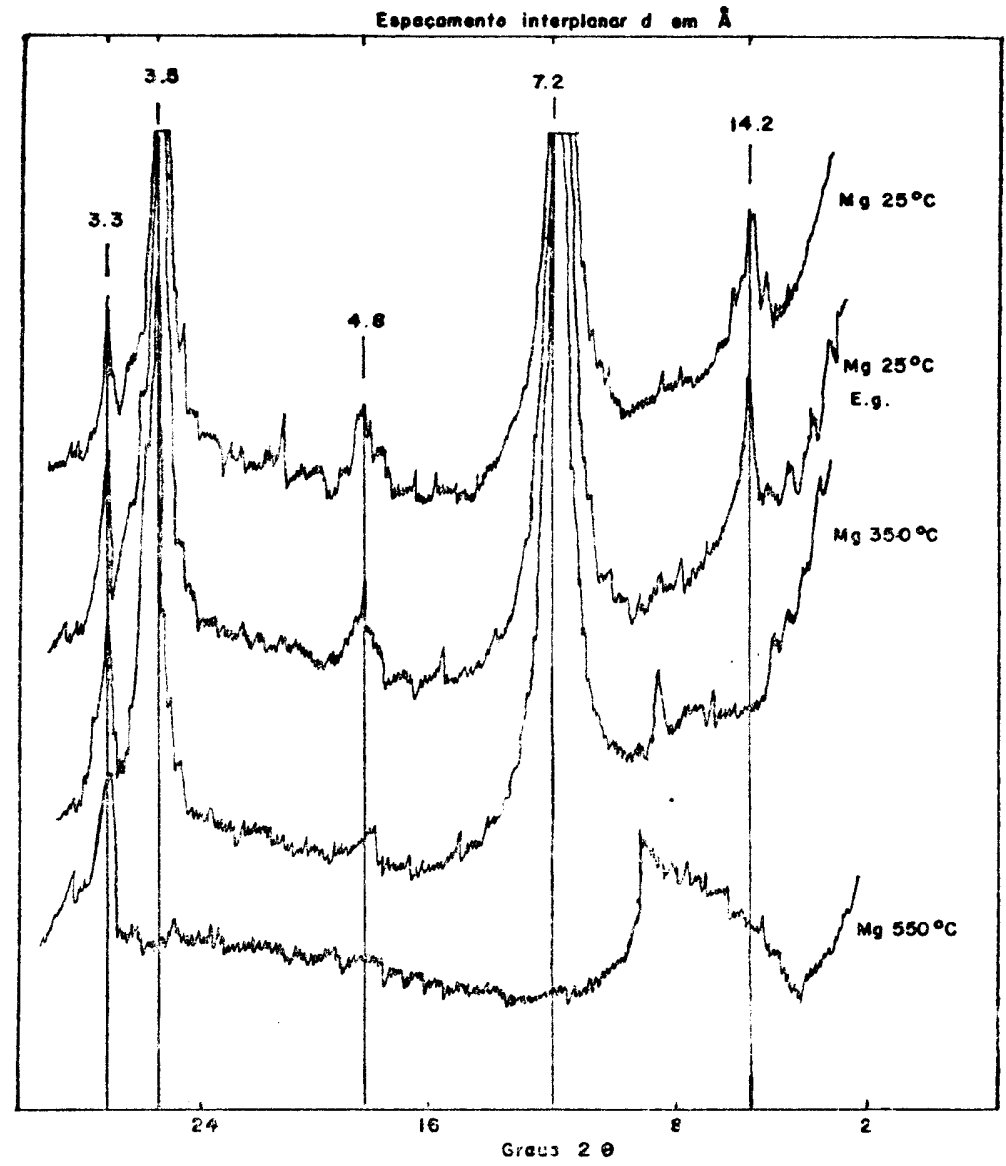

Espogamanto intarplener d em a

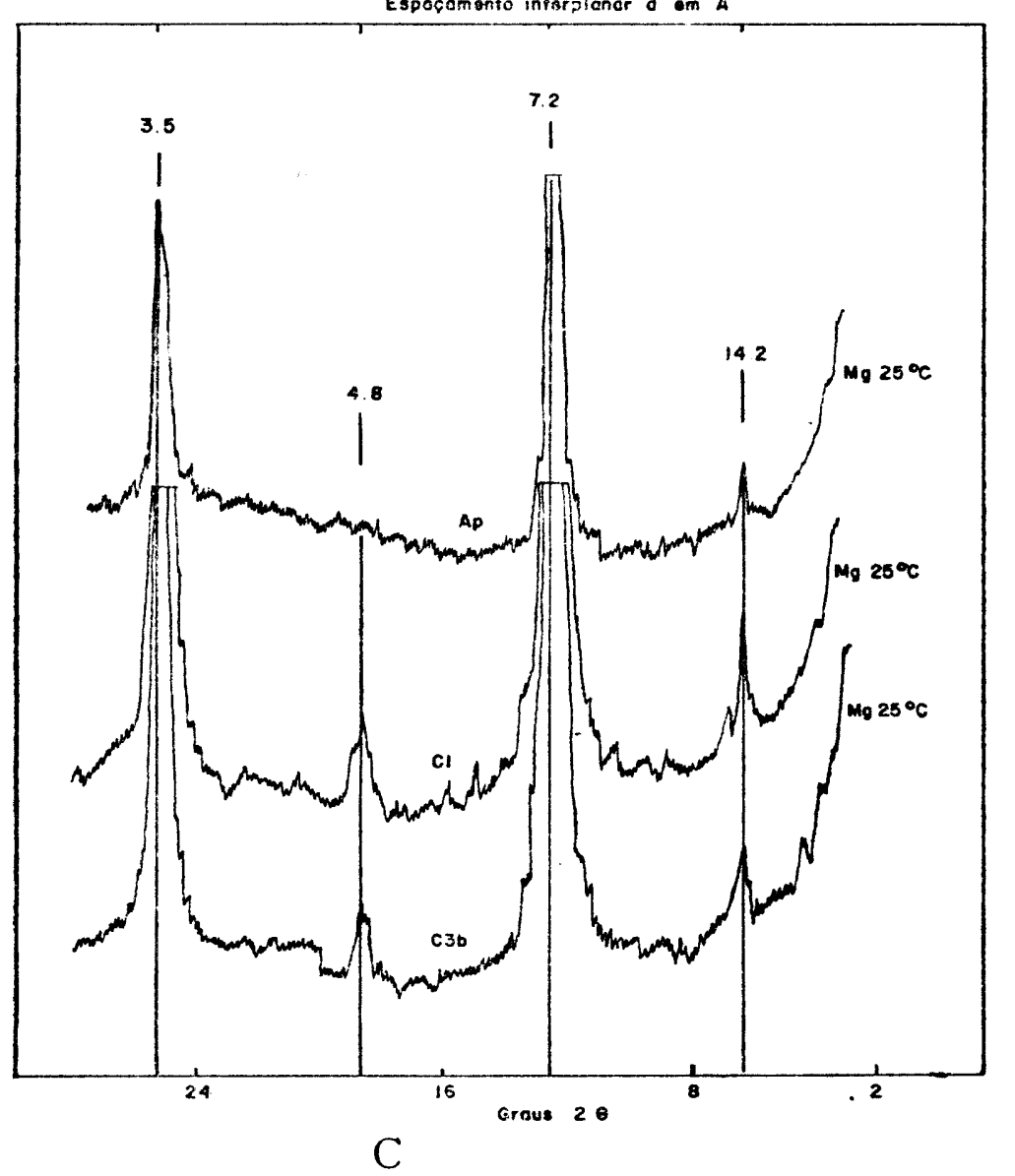

B

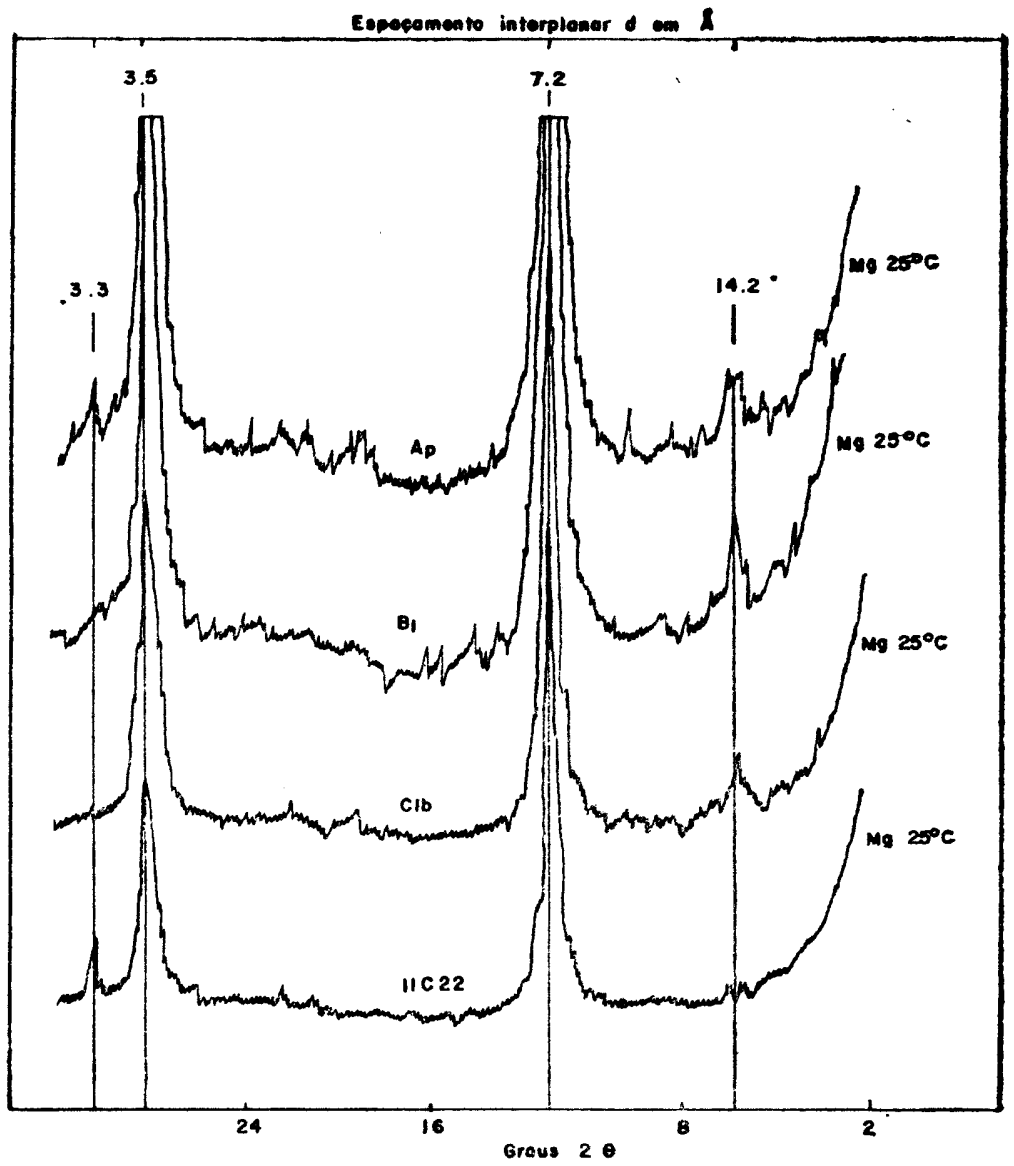

Espocamento inforplonar of om 4

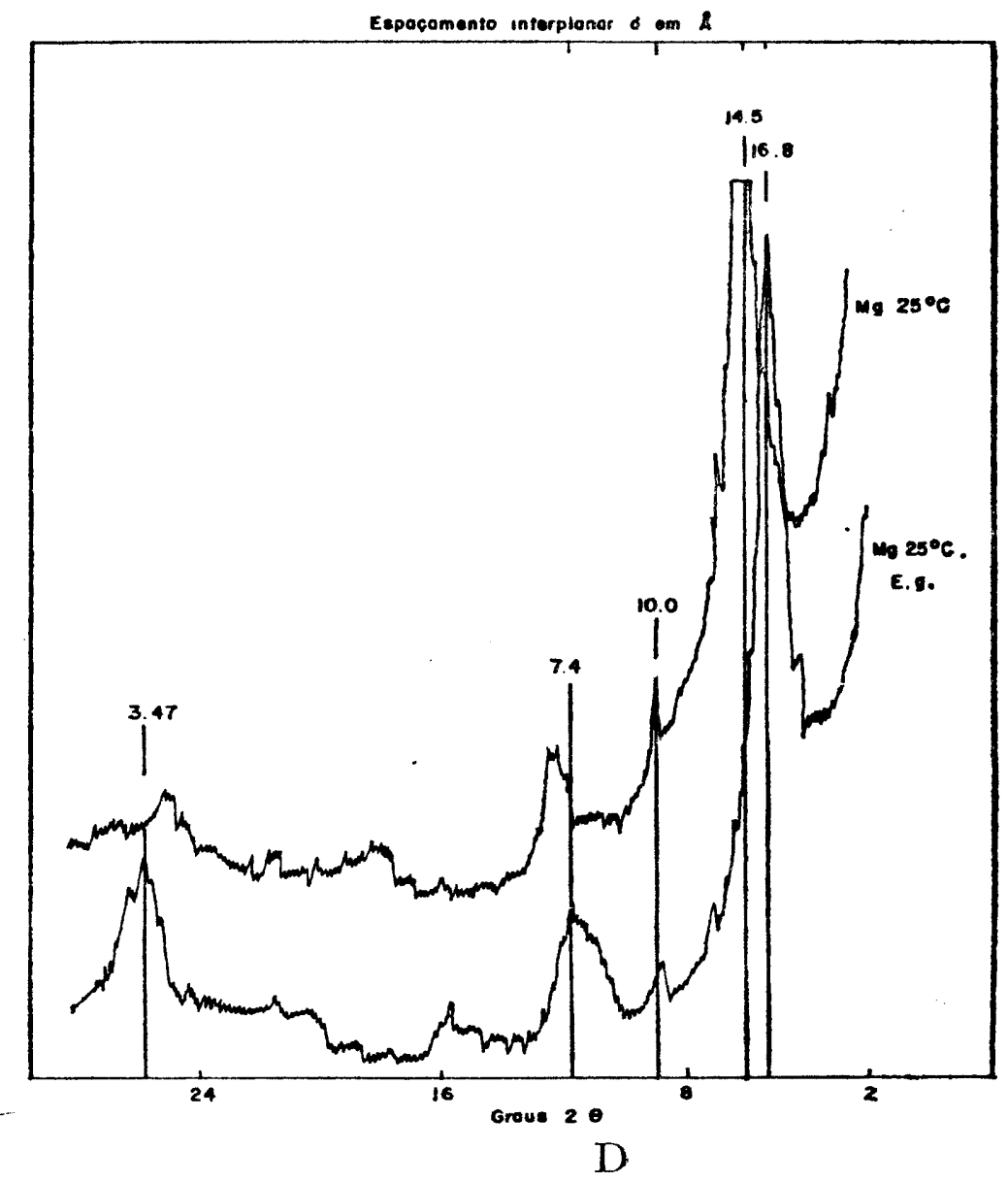

Figura 2 - Difração dos raios $\mathrm{x}$ das frações argila, Pedon 1 (A), Pedon 2 (B), Pedon 4 (C) e Pedon 3 (D) 


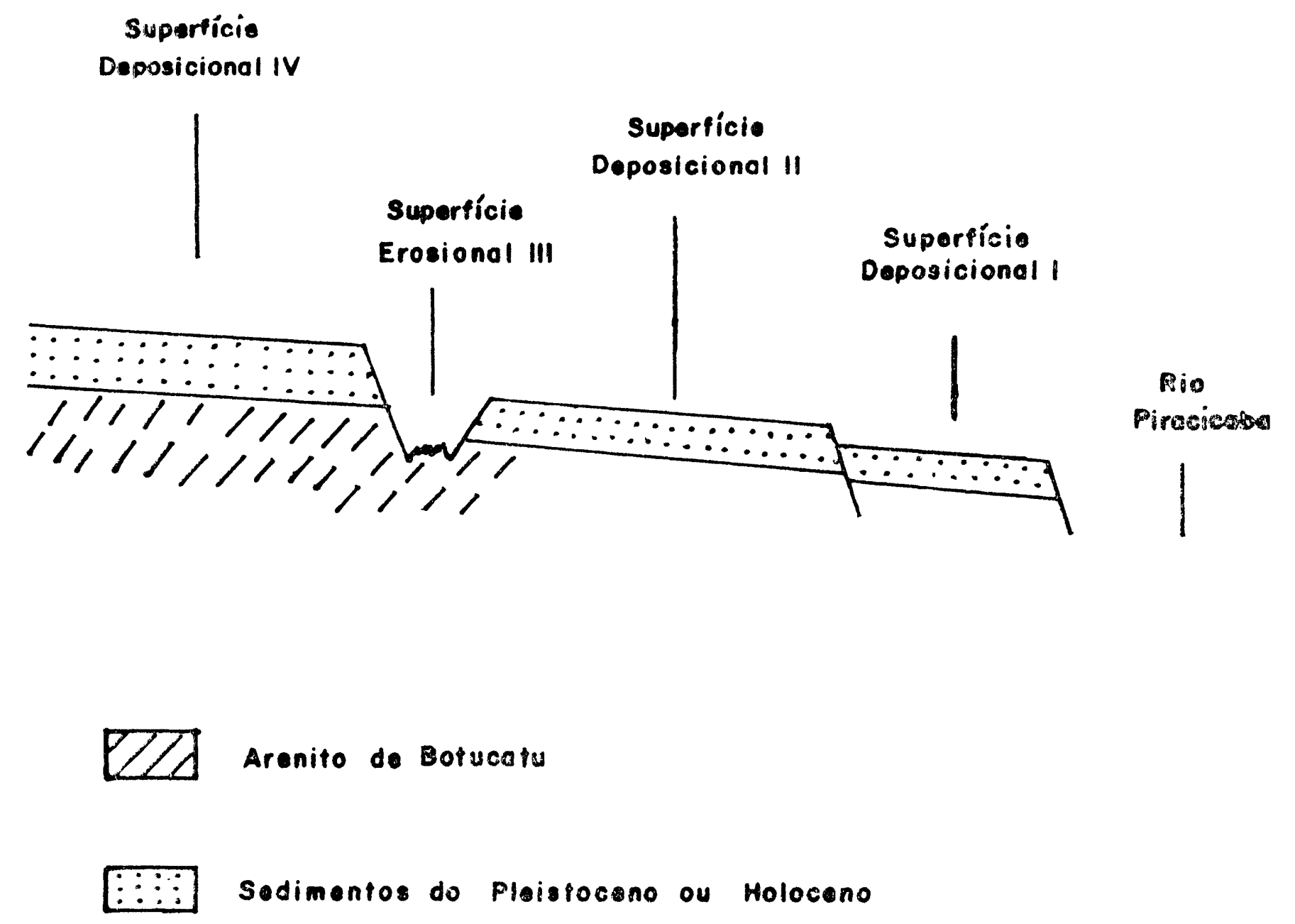

Figura 3 - Esquema das superficies fisiográficas localizados na Depressão Paleozóica 
De uma maneira geral os dados mineralógicos indicam que:

a) Pedon 3 possue os teores mais elevados de minerais de grade 2:1 (em certos horizontes mais de $50 \%$ ). Os teores destes minerais nos outros solos decrescem na seguinte ordem: Pedon $1>$ Pedon $2>\mathrm{Pe}-$ dons 4 e 5 .

b) Pedon 3 possue o teor mais elevado de mica, seguido pelo Pedon 1. Quantidades neglegíveis são apontadas para os demais solos.

c) O Pedon 3 possue o mais baixo teor de caulinita, média de $49 \%$ para o solum.

Utilizando estes dados mineralógicos como índice de intemperismo (Jackson et alii, 1948) pode-se afirmar que o Pedon 3 é o mais jovem sendo seguido a ordem de intemperismo apresentada em $a$. Se estas idades relativas de solos obtidas através da mineralogia forem utilizadas como indicadoras de idades de superfícies fisiográficas a ordem será a seguinte, indo da mais jovem para a mais velha:

Superfície III < Superfície I $<$ Superfície II $<$ Superfície IV

De acordo com os critérios de idades de superfícies (Daniels, et alii, 1971) a Figura 3 foi construída e as seguintes generalizações são válidas:

a) A Superfície IV é a mais velha (é a mais alta)

b) A Superfície III (Superfície erosional) corta as Superfícies IV e II e portanto é mais jovem que ambas.

c) A Superfície I é mais jovem que a Superfície II pois está abaixo desta.

d) A Superfície III, que é erosional, corta o substrato rochoso, então é mais jovem que a Superfície I.

Consequentemente a sequência de idade relativa de superfícies obtidas utilizando os critérios de Daniels et alii (1971) coincide com a mesma sequência obtida utilizando os dados mineralógicos.

Os solos dạs superfícies elevadas (Superfícies V e VI) são representados pelos pedons 6, 7 e 8. Caulinita e gibbsita (Figura 4) são os argilo-minerais dominantes. Os dados também mostram que a medida que o teor de caulinita decresce o de gibbsita cresce. Dentre os minerais de grade 2:1 a vermiculita é o que mais ocorre porém em quantidades abaixo de $5 \%$. 

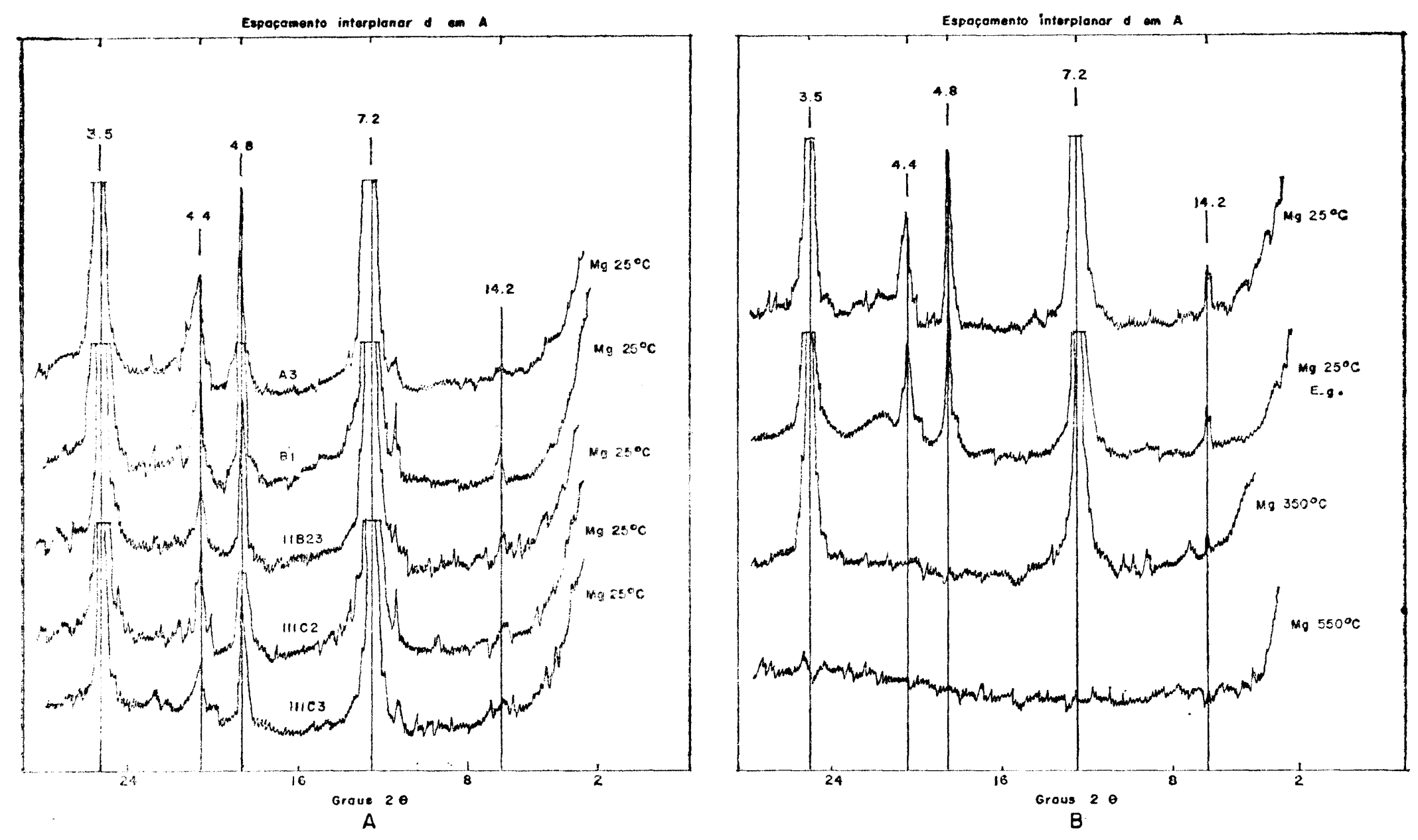

Espaçomento interplanar a om A
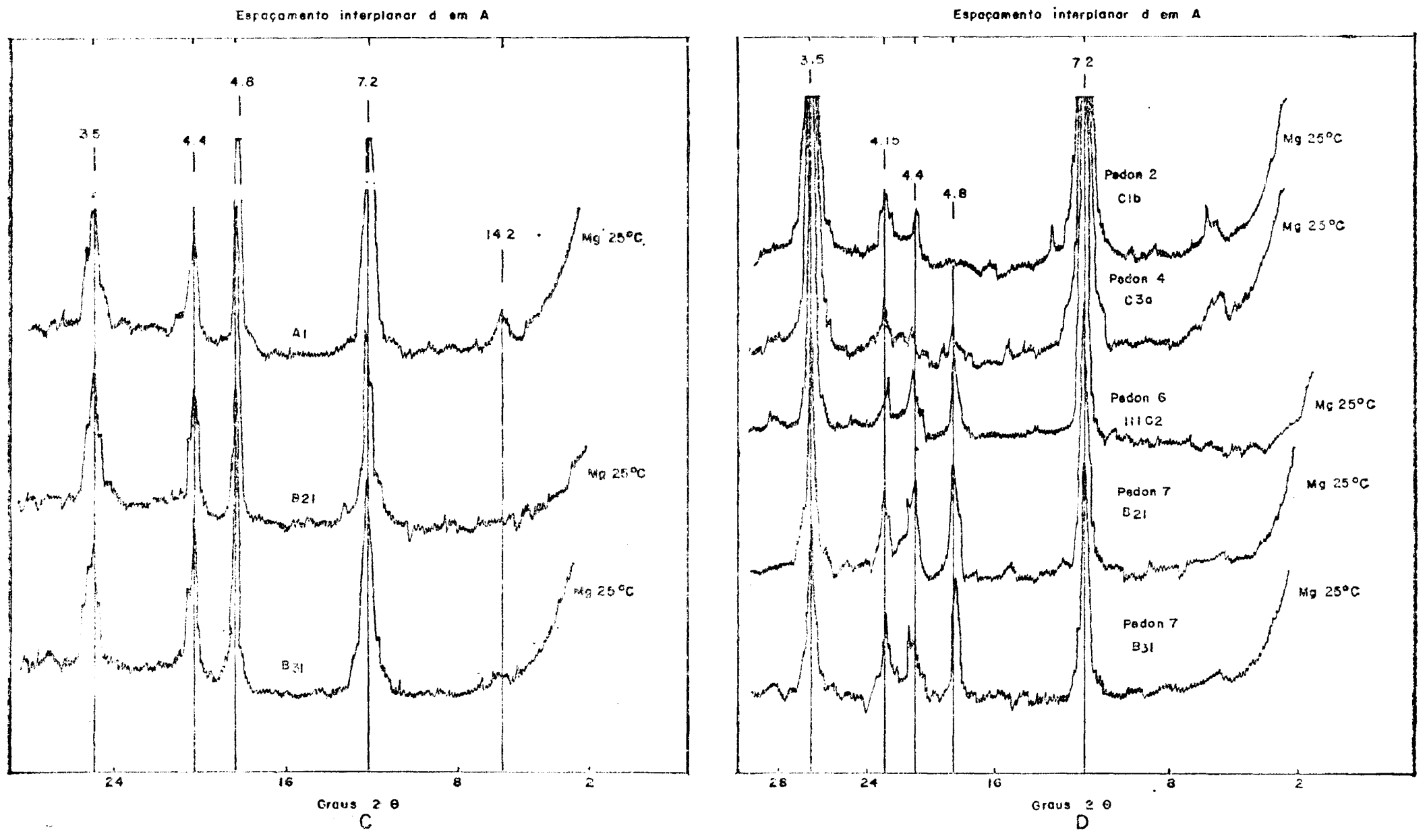

Figura 4 - Difração dos raio-X da fração argila, Pedons 6,7 e 8 (A, B e C). Amostras não tratadas, Pedons 2, 4, 6 e 7 (D). 
Utilizando a gibbsita (Quadro 1) como um índice de intemperismo pode-se afirmar que o Pedon 6 é o mais jovem seguido pelos Pedons 7 e 8. Esta sequência mineralógica não concorda, entretanto, com a posição topográfica ocupada pelas duas superfícies (Figura 1B). De acordo com os critérios adotados por Daniels et alii (1971) as relações das superfícies é a seguinte:

a) A Superfície VI (Superfície deposicional) é a mais elevada, consequentemente a mais velha. Portanto o Pedon 6 é o mais velho.

b) Desde que a Superfície $V$, também deposicional, esteja em cota mais baixa ela é mais jovem. Consequentemente os Pedons 7 e 8 são mais jovens do que o Pedon 6 .

Este resultado indica portanto que a mineralogia dos Pedons 6, 7 e 8 não deve ser utilizada como um critério para o estabelecimento de idade relativa de superfícies.

O espaçamento de 4,15 A (Figura 4) indica a presença de goethita em todos os solos investigados, sendo mais abundante no Pedon 7. Esta elevada quantidade de goethita, na fração argila, está relacionada com o elevado teor de ferro livre (Quadro 1). A hematita também foi constatada porém em menor quantidade. O espaçamento de 2,56 A, característico deste mineral está presente em todos os difratogramas estudados mas devido a problemas de escala não foi incluído na Figura 4.

A formação de minerais interestratificados em solos ácidos muito intemperizados (caso dos Pedons, 6, 7 e 8) pode ser devido a precipitação de hidróxido de $\mathrm{Al}$ entre as lâminas de vermiculita (Jackson, 1964). Devido a tais características este mineral é relativamente estável em condições tropicais. A alteração da mica para vermiculita (Borchardt et alii, 1966) em solos de clima temperado parece ser um estágio intermediário na alteração mica para caulinita em solos tropicais pois a vermiculita sempre está presente em todos os solos estudados. Em vista da baixa resistência da mica (ilita) ao intemperismo em comparação com a caulinita e vermiculita, a mica identificada nestes solos ácidos foi provavelmente herdada do material originário do que sentetizada durante o presente ciclo pedogenético. A caulinita pode ter sido sintelizada durante o processo pedogenético assim como herdada do material originário. Condições ácidas e de boa drenagem são favoráveis a formação de caulinita a partir de minerais de grade 2:1. A presença de gibbsita nestes solos pode ser explicada através da dessilicatização da caulinita (Jackson, 1965). 
Anais da E. S. A. "Luiz de Queiroz"

\section{CONCLUSÕES}

A fração argila da maioria dos solos estudados é constituída predominantemente por caulinita (para os solos das superfícies mais baixas) e caulinita e gibbsita (para os solos das superfícies mais elevadas).

Pedon 3 possue uma composição totalmente diferente; o teor de minerais de grade 2:1 representado pela mica, vermiculita e montmorilonita é elevado, variando entre 30 a $70 \%$. Tanto a mica como a montmorilonita foram herdadas do material de origem. Nos demais solos o teor de minerais 2:1 é baixo (menor que $8 \%$ ), representado principalmente pela vermiculita. De acordo com o intemperismo médio os solos foram colocados na seguinte ordem crescente ao intemperismo: Pedon $3<$ Pedon $1<$ Pedon $2<$ Pedon 4 e $5 \leqslant$ Pedon $6<$ Pedon 7 $<$ Pedon 8.

Para os solos das superfícies baixas existe correlação entre idade das superfícies fisiográficas e mineralogia da argila.

\section{SUMATRY}

\section{SOME MINERALOGICAL CHARACTERISTICS OF A TOPOSEQUENCE OF SOILS FROM SÃO PEDRO REGION, SÃO PAULO STATE}

Eight pedons representing soils found on successivcly higher landscapes along a $25 \mathrm{~km}$ transect north of Piracicaba River were investigate as to their clay mincralogical properties. The clay fraction in most of the soils is composed predominantly of kaolinite and gribbsite. Gibbsite is most prevalent in the soils exhibiting the most weathering. Pedons located on lower surface have a content of gibbsite of less tran $6 \%$ and pedons located on higher surfaces $i$, e. Pedons 6,7 and 8 , have a gibosite content within the range of $12-54 \%$. Pedons 3 has a different mineralogical coposition; the amount of 2:1 minerals represented by mica, vermiculite and montmorillonite is large, estimated values ranging from 30 to $70 \%$ of the clay. In the other soils the $2: 1$ mineral is represented mainly by vermiculite in low amounts (less than $8 \%$ ) and it is lower in soils on the higher surfaces.

For the lower surfaces there is a correlation between clay mineralogy and the positulated relative ages of surface. This relationship is not apparent in soils located on the higher surfaces. Transformation of kaolinite to gibbsite is suggested by the results oltained on relative quantities of these mineral species found in the soils investigated.

\section{ITTERATURA CITADA}

ALEXIADES, C.A., \& JACKSON, M.L. - Quantitative determination of vermiculite in soils. Soil Sci. Soc. Amer. Proc. 29: 522-527. 1965. 
ALEXIADES, C.A., \& JACKSON, M.L. - Quantitative clay mireralogical analysis of soils and sediments. Clays and Clay Minerals. Proc. 14th. Conf. pp 35-52. 1966.

ALMEIDA, F.M. de - Fundamentos geológicos do Relevo Paulista. Inst. Geog. e Geol. Bul. 41: 169-263. São Paulo. 1964.

BORCHARDT, G.A., JACKSON, M.L., \& HOLE, F.D. - Expandible layer silicate genesis in soils depicted in mica peseudomorphs. Proc. Int. Clay Conference. 1: 175-185. Jerusalem. 1966.

DANIELS, R.B., GABLE, E.E., \& CADY, J.G. - The relation between geomorphology and soil morphology and genesis. Adv. in Agronomy 23: 51-89. 1971.

DEMATTE, J.L.I. - Characteristics and classification of a toposequence of soils near Piracicaba, Brazil. Ph.D. Dissertation. The Ohio State University. 1975.

DIXON, J.B. - Quantitative analysis of kaolinite and gibbsita in soils by differential thermal and selective dissolution methods. Clays and Clay Minerals Proc. 14th Conf. pp. 83-89. 1966. 
